\title{
The effect of practicing traditional dances on selected psychological variables in high school students in Ethiopia
}

\author{
(D) Mulay Gebretensay ${ }^{1}$, (D) Soumitra Mandal ${ }^{1}$, (D) Dhamodharan Mathivanan ${ }^{1}$, \\ (D) Mahmud Abdulkader ${ }^{2}$, (D) Gebretsadik Gebru ${ }^{3}$, (D) Kedir Mohamedhusien ${ }^{3}$ \\ ${ }^{1}$ Department of Sport Science, College of Natural and Computational Sciences, Mekelle University, Mekelle, Ethiopia. \\ 2 Institute of Medical Microbiology E Immunology, College of Medical science, Mekelle University, Mekelle, Ethiopia \\ ${ }^{3}$ Department of Statistics, College of Natural and Computational Sciences, Mekelle University, Mekelle, Ethiopia.
}

\begin{abstract}
The purpose of the present investigation was to evaluate the effect of practicing Tigray Regional State Traditional Dances on selected psychological variables, i.e. anxiety and self-esteem, in a sample of one 100 adolescent boys and girls (age $15-17$ years) who volunteered. The subjects were divided into two groups i.e., the experimental group $(n=80)$ and the control group $(n=20)$. Furthermore, the experimental group was divided into four subgroups $(\mathrm{n}=4 \mathrm{X} 20)$. Each experimental subgroup was practicing for 16 weeks one of the four Traditional Dances of Awris, Hura, Kuda and Shediva. On the contrary, the participants in the control group were counseled to follow their usual daily routine activity. Additionally, all participants were tested on selected criterion measures on anxiety and self-esteem prior to and after the investigation period which lasted for 16-weeks. All data were statistically examined using ANOVA for each one of the studied variables separately. Whenever ' $\mathrm{F}$ ' ratio of adjusted post-test was found to be significant the Scheffe's test was used to determine the paired mean differences. The level of significance was set at $\mathrm{p}<0.05$. Following the 16-weeks traditional dance practicing, significant positive changes were observed on anxiety and self-esteem variables in the four experimental groups compared with the control group. It can be, therefore, concluded, that Tigray traditional dance practicing can notably improve the psychological wellbeing of high school students.
\end{abstract}

Keywords. Anxiety, self-esteem, traditional dance, wellbeing.

\section{Introduction}

Ethiopia is a widely diverse country with over eighty unique, rich ethnic, cultural, custom and linguistic groups. Each ethnic group has its own traditional rhythm and dance style in order to preserve and perpetuate certain ideas, religious beliefs, historical events, ancient stories and thoughts. Due to its old history, one that dates back to 3000 years, Ethiopia's folk dance is a symbol of their mosaic culture (Ethiopian-folk-dance, 2018). Dancing is, indeed, an integrated part of life for Ethiopian's. Consequently, they enjoy dancing in their social and spiritual function.

Ethiopia has many ethnic groups and languages, along with a large diversity of music and dance kinds. Although most of them are indigenous, it is believed that Wolaytigna (Southern Nations, Nationalities, and Peoples' Region could be the origin music and dance of Africa, whereas music and dance of Amharic (Amhara region), Afan Oromo (Oromia region), Tigirigna (Tigray region),

Received: February 5, 2019 - Accepted: March 5, 2019 - Published: March 30, 2019

To cite this article: Gebretensay M, Mondal S, Mathivanan D, Abdulkader M, Gebru G, Mohamedhusien K. The effect of practicing traditional dances on selected psychological variables in high school students in Ethiopia. Turk J Kinesiol, 2019; 5(1): 22-27.

M. Gebretensay, e-mail: mulay_atahan@yahoo.com

DOI: $10.31459 /$ turkjkin.522682 
Gurageagna (Southern Nations, Nationalities, and Peoples' Region), Afarigna (Afar region), Sidamigna (Southern Nations, Nationalities, and Peoples' Region), Gambela (Gambela region), etc. are not yet well known to the other world. Additionally, all of the above areas have their own dances and rhythms and even each kind of their music has its own divisions (Teffera, 2006).

Tigray is one of the nine regions of Ethiopia which has enriched cultural background. The traditional dances of Tigray region are characterized by twobeat drum rhymes. According to the distinctive drum rhymes, participants dance in a circle like in the Japanese Bon Dance. These dances have also different variety of steps, such as delicate neck motion, rhythmical shoulder movement, jumping steps and so on (Horwitz, 1997).

Several studies have proved that traditional dance can significantly increase the psychological wellbeing variables of students (Mavrovouniotis et al., 2010). However, there is little epidemiological data on the effect of traditional dance practicing on psychological wellbeing in Ethiopian adolescences. Therefore, the purpose of the present study was to investigate the effect of practicing traditional dances of Tigray regional state i.e., Awris, Hura, Kuda and Shediva, on selected psychological variables, namely, anxiety and self-esteem. Hopefully, the implication of such study will enrich the information about the relation of traditional dances with psychological variables. Furthermore, it may assist and urge psychologists, health care experts, coaches, athletes and individuals to incorporate traditional dance practicing in their strategies in physical exercise programs aiming at improving psychological wellbeing.

\section{Methods}

\section{Subjects}

For the purpose of the present study, the total of 100 healthy boys and girls (age 15 - 17 years) volunteered. They were randomly selected out of a total of 207 students from grade nine and ten of Mekelle University community school using the scientific sample determination technique, namely the Thompson's (2012) formula: $\boldsymbol{n}=\frac{1}{\frac{1}{n \mathbf{0}}+\frac{1}{N}} \quad$ Where: $\mathrm{n}$ is sample size; $\mathrm{n}_{\mathrm{o}}$ is before considering the sample; $\mathrm{N}$ is total population; Confidence level was 95\%; Precision level was $\pm 7 \%$; Maximum variability was 0.5 .

\section{Ethical considerations}

Specific ethical guide lines were adhered to while conducted the research. Before conducted the study, ethical clearance was obtained from the ethical committee Ayder Referral Hospital of Mekelle University.

Another important ethical consideration was that, professionals must respect the right and dignity as well as the attitude, beliefs and opinions of the participants. During the intervention it was kept in mind that the participants have the right to withdrew from the study at any time. This was made clear to them during the briefing session of the study as well as in the consent and assent form that they and their parents or guardians signed. The participants and their parents or guardians were assured of their anonymity and that confidentiality was maintained at all times.

Furthermore, the health, dance professionals and the researcher must avoid harm to the participants at all times. During each session the participants was undergo through warming up and cool down procedure to prevent physical injury.

Lastly, the intervention with each participant was carried out in sensitive manner and no pressure was placed on them to do anything with which they did not feel comfortable.

A warm and friendly environment was created and the researcher was act in the best interest of each participants.

\section{Study design}

A randomized controlled parallel trial was used for this study as it was considered as the most 
appropriate (Haakstad et al., 2016) for the purpose of the present study. All the 100 participants were randomly categorized into four experimental and one control groups. Each group consisted of twenty participants $(n=20)$. The experimental group was practicing the four traditional dances of Tigray regional state (Awris, Hura, Kuda and Shadiva) for a period of 16-weeks, excluding the period utilized for pre-test and post-test. The control group was not participating in any of the traditional dance training program given to the experimental groups during the experimental period. Namely, they were counseled to follow their usual daily routine activity such as actively participated in the school teachinglearning activities, helping their families at home and so on.

\section{Data collection tools}

To collect data, first permission was taken from the respective sources that were from administrators, parent/guardian, students and experts. All the necessary information about the study was explained to the participants in advance. All the participants were orient to fill full the psychological questions (Anxiety: Generalized anxiety disorder 7item (gad-7) scale (Spitzer, 2006) and self-esteem: Rosenberg Self-Esteem Scale (Rosenberg, 1965)). Having this necessary data was collected in both the pre and post-tests using the same procedure and the higher scores indicate highest self-esteem and viseversa in Anxiety.

Table 1

Variables and Criterion Measures.

\begin{tabular}{lll}
\hline Sr.No & Variables & Tests used \\
\hline \multirow{2}{*}{1} & Anxiety & Generalized anxiety disorder 7-item (gad-7) scale (Spitzer, 2006) \\
\cline { 2 - 3 } & Self- esteem & Rosenberg Self-Esteem Scale (Rosenberg, 1965) \\
\hline
\end{tabular}

Table 2

Training protocol.

\begin{tabular}{|c|c|c|c|c|c|c|c|}
\hline \multicolumn{3}{|c|}{ Number of weeks and intensity } & \multirow[b]{2}{*}{$\begin{array}{c}\text { Types of } \\
\text { Traditional dances } \\
\text { of Tigray region }\end{array}$} & \multirow[b]{2}{*}{$\begin{array}{l}\text { Duration } \\
\text { (min) }\end{array}$} & \multirow[b]{2}{*}{$\begin{array}{l}\text { Repetition } \\
\text { (n) }\end{array}$} & \multirow[b]{2}{*}{$\begin{array}{l}\text { Rest } \\
\text { (sn) }\end{array}$} & \multirow[b]{2}{*}{$\begin{array}{c}\text { Frequency } \\
\text { per week }\end{array}$} \\
\hline $\begin{array}{c}\text { 1st to 4th } \\
\text { Weeks } \\
\text { Phase I }\end{array}$ & $\begin{array}{c}\text { 5th to 10th } \\
\text { Weeks Phase } \\
\text { II }\end{array}$ & $\begin{array}{c}\text { 11th and 16th } \\
\text { Weeks Phase } \\
\text { III }\end{array}$ & & & & & \\
\hline $60 \%$ & $70 \%$ & $80 \%$ & Awris & $5: 58 \min$ & & & \\
\hline \multirow[t]{10}{*}{ THR } & THR & THR & & $\begin{array}{l}5: 85 \mathrm{~min} \\
6: 13 \mathrm{~min}\end{array}$ & 6 & $30 \mathrm{sec}$ & \\
\hline & & & Hura & $6: 13 \mathrm{~min}$ & & & \\
\hline & & & & $6: 30 \mathrm{~min}$ & 5 & $30 \mathrm{sec}$ & \\
\hline & & & & $6: 37 \mathrm{~min}$ & & & 3 \\
\hline & & & Kuda & $6: 10 \mathrm{~min}$ & & & (Three days) \\
\hline & & & & $6: 66 \mathrm{~min}$ & 4 & $30 \mathrm{sec}$ & \\
\hline & & & & $7: 12 \mathrm{~min}$ & & & \\
\hline & & & Shediva & $4: 29 \mathrm{~min}$ & & & \\
\hline & & & & $5: 45 \mathrm{~min}$ & 7 & $30 \mathrm{sec}$ & \\
\hline & & & & $4: 67 \mathrm{~min}$ & & & \\
\hline
\end{tabular}




\section{Statistical Analyses}

Under the guidance of a statistician, the SPSS (version 25 for Windows) statistical package was utilized for all statistical analyses and the statistical significance was set at $\mathrm{p}<0.05$. Descriptive statistics, mean and standard deviation were found in order to get the basic idea of the data distribution. The significance of adjusted post-test mean differences between the experimental and control group for each variable ANOVA (Analysis of variance) test was utilized. Whenever the ' $F$ ' ratio was found to be significant, Scheffe's test was used to determine which of the paired means differed significantly.

\section{Results}

The following 3 \& 4 Tables illustrate the statistical results as an effect of Traditional dances of Tigray regional state on Anxiety and Self-esteem among all participants.

The results presented in Table 3 indicate that, the Traditional dance treatment groups had shown significant improvement in psychological variables namely Anxiety and Self-esteem when compared with the control group as well as with the base line data after they underwent the sixteen weeks Traditional dance practicing program.

Moreover, Table 4 revealed that, significant differences were observed among all groups in the Anxiety criterion. However, there were no significant difference observed in Self-esteem except among Kuda, Shediva, Awris and Hura and control group.

\section{Discussion}

Traditional dancing is an excellent form of exercise because besides the fact that it improves the general physical fitness (Hui et al., 2009), it is also an important contributing factor to an overall sense of happiness and wellbeing (Cynthia et al,. 2010). For instance, examining the impact of a traditional Greek dance program on seven year old schoolchildren (Iordanidou, 2012) and elderly (Zilidou et al., 2015), with regard to psychosocial variables, found significant improvement in their self-esteem and

Table 3

Analysis of variance for the pre -test and post- test data on Anxiety and Self-esteem score of Awris, Hura, Kuda, Shediva and Control Groups.

\begin{tabular}{|c|c|c|c|c|c|c|c|c|c|c|c|c|}
\hline Variables & Tests & & $\begin{array}{l}\text { Awris } \\
\text { Dance }\end{array}$ & $\begin{array}{c}\text { Hura } \\
\text { Dance }\end{array}$ & $\begin{array}{l}\text { Kuda } \\
\text { Dance }\end{array}$ & $\begin{array}{c}\text { Shediva } \\
\text { Dance }\end{array}$ & $\begin{array}{l}\text { Control } \\
\text { Group }\end{array}$ & SoV & SoS & $\mathrm{df}$ & MS & $\mathrm{F}$ \\
\hline \multirow[t]{6}{*}{ Anxiety } & PrT & Mean & 14.15 & 13.60 & 15.00 & 14.50 & 15.20 & B & 33.440 & 4 & 8.360 & 1.212 \\
\hline & & SD & 3.28 & 3.33 & 2.42 & 2.23 & 1.32 & W & 655.550 & 95 & 6.901 & \\
\hline & PoT & Mean & 8.25 & 9.30 & 12.45 & 8.90 & 15.50 & $\mathrm{~B}$ & 742.860 & 4 & 185.715 & $78.865^{*}$ \\
\hline & & SD & 1.44 & 1.71 & 1.39 & 1.88 & 1.10 & W & 223.700 & 95 & 2.355 & \\
\hline & APT & Mean & 8.298 & 9.424 & 12.379 & 8.899 & 15.401 & B & 686.139 & 4 & 171.535 & $76.459 *$ \\
\hline & & & & & & & & W & 210.887 & 94 & 2.243 & \\
\hline \multirow{6}{*}{$\begin{array}{l}\text { Self- } \\
\text { esteem }\end{array}$} & PT & Mean & 24.55 & 22.90 & 23.30 & 23.25 & 23.44 & B & 32.740 & 4 & 8.185 & 0.762 \\
\hline & & SD & 2.70 & 4.49 & 2.86 & 2.69 & 3.26 & $\mathrm{~W}$ & 1019.900 & 95 & 10.736 & \\
\hline & PST & Mean & 34.10 & 34.05 & 33.90 & 33.95 & 32.27 & B & 1197.660 & 4 & 299.415 & $45.580^{*}$ \\
\hline & & SD & 2.61 & 2.48 & 2.67 & 2.50 & 4.28 & W & 624.050 & 95 & 6.569 & \\
\hline & $\mathrm{APT}$ & Mean & 34.045 & 34.077 & 33.907 & 33.959 & 2.362 & B & 1191.740 & 4 & 297.935 & $45.058^{*}$ \\
\hline & & & & & & & & W & 621.554 & 94 & 6.612 & \\
\hline
\end{tabular}

PrT: Pretest; PoT: Posttest; APT: Adjusted Posttest; SoV: Source of Variation; B: Between samples; W: Within samples; SoS: Sum of Squares; MS: Mean Squares.

$\mathrm{F}(4,95 ; 4,94)=2.46$; ${ }^{*}$ Significant at $\mathrm{p}<0.05$ level of confidence. 
Table 4

Scheffe's test for differences of the adjusted post-test paired means of Anxiety and Self-esteem.

\begin{tabular}{|c|c|c|c|c|c|c|c|}
\hline \multicolumn{6}{|c|}{ Adjusted Post-test Mean } & \multirow{2}{*}{$\begin{array}{c}\text { Mean } \\
\text { Differences }\end{array}$} & \multirow{2}{*}{$\begin{array}{l}\text { Confidence } \\
\text { Interval }\end{array}$} \\
\hline Variables & $\begin{array}{l}\text { Awris } \\
\text { Dance }\end{array}$ & $\begin{array}{l}\text { Hura } \\
\text { Dance }\end{array}$ & $\begin{array}{l}\text { Kuda } \\
\text { Dance }\end{array}$ & $\begin{array}{l}\text { Shediva } \\
\text { Dance }\end{array}$ & $\begin{array}{l}\text { Control } \\
\text { Group }\end{array}$ & & \\
\hline \multirow[t]{10}{*}{ Anxiety } & 8.298 & 9.424 & & & & $1.126^{*}$ & 0.47 \\
\hline & 8.298 & & 12.379 & & & $4.081^{*}$ & \\
\hline & 8.298 & & & 8.899 & & $0.601^{*}$ & \\
\hline & & 9.424 & 12.379 & & & $2.955^{*}$ & \\
\hline & & & 12.379 & & 15.401 & $3.022^{*}$ & \\
\hline & & & & 8.899 & 15.401 & $6.502^{*}$ & \\
\hline & 8.298 & & & & 15.401 & $7.103^{*}$ & \\
\hline & & 9.424 & & & 15.401 & $5.977^{*}$ & \\
\hline & & & 12.379 & 8.899 & & $3.480^{*}$ & \\
\hline & & 9.424 & & 8.899 & & $0.525^{*}$ & \\
\hline \multirow[t]{10}{*}{ Self- esteem } & 34.045 & 34.077 & & & & 0.032 & 0.81 \\
\hline & 34.045 & & 33.907 & & & 0.138 & \\
\hline & 34.045 & & & 33.959 & & 0.086 & \\
\hline & & 34.077 & 33.907 & & & 0.170 & \\
\hline & & & 33.907 & & 25.362 & $8.545^{*}$ & \\
\hline & & & & 33.959 & 25.362 & $8.597^{*}$ & \\
\hline & 34.045 & & & & 25.362 & $8.683^{*}$ & \\
\hline & & 34.077 & & & 25.362 & $8.715^{*}$ & \\
\hline & & & 33.907 & 33.959 & & 0.052 & \\
\hline & & 34.077 & & 33.959 & & 0.118 & \\
\hline
\end{tabular}

* Significant at $\mathrm{p}<0.05$ level

mental health, respectively. A similar study (Maraz et al,. 2015) showed that a dancing program increased self-esteem and reduced anxiety high school and college students. In line with the above investigations, Olvera (2008) suggested that, a cultural dance program was used in order to prevent anxiety and improve other psychological variables of wellbeing. In addition, Brennan (2012), demonstrated positive associations between traditional dance practicing and psychosocial Wellbeing.

As anticipated, the present findings also indicate that, the 16-weeks Traditional dance practicing program significantly improved the psychological variables, namely, Anxiety and Self-esteem of high school Ethiopian students. These results complement the above named previous reports demonstrating positive associations between traditional dance practicing and the general psychological wellbeing improvement.

Moreover, dancing facilitates the release of endorphins through to the combined effect of physical activity and music on the state of mind (Parker, 2015; Whitman, 2017). It is well known that endorphins are released when the body is forced to exert itself at a certain level, as it happens in the case of the 'runner's high' (Schwarz, 1992). As dancing is a quite similar activity, this very same boost in mood can be achieved through its practicing with the intensity of $60-80 \%$ THR. Truly, the physical exertion which is achieved through dancing facilitates the joined release of endorphins and adrenaline which in turn create a dramatic 'dancer's high' (Parker, 2015). As an aerobic exercise, traditional dance brings well known benefits in improving psychological well-being (Taylor, 1995), increase 
self-esteem (Murcia et al., 2010), reduce anxiety (Leste, 1990) and it also elevate mood and increase social contact in a healthy adolescent females (Blackman et al., 1988; Estivill, 1995). Therefore, Tigray traditional dances played using all forms and combinations of stamping, jumping, skipping, shaking, turning and twisting is an evident to achieve the psychological well-being of high school students

\section{Conclusion}

Within the limitations of the present study, it was concluded that, the Traditional dance practicing groups had shown significant improvement in the studied psychological variables namely Anxiety and Self-esteem when compared with the control group as well as the base line information after they underwent 16-weeks of Tigray Traditional dance practicing.

\section{Acknowledgements}

The researchers wish to acknowledge the Department of Sport Science, College of Natural and Computational Sciences and Mekelle University for the support and approval to carry out the study. We also appreciate the enthusiasm and co-operation of the participants.

\section{References}

Blackman L, Hunter G, Hilyer J, Harrison P. The effects of dance team participation on female adolescences. Adolescence, 1988; 23(90), 437-448.

Ethiopian-folk-dance [Internet]. 2018. Available from: https://bawza.com/2017/12/28/introducingethiopian-folk-dance/.

Haakstad LAH, Edvardsen E, Bø K. Effect of regular exercise on blood pressure in normotensive pregnant women. A randomized controlled trial. Hypertens in Pregnancy, 2016; 35(2): 170-80. doi: 10.3109/10641955.2015.1122036.

Horwitz DL. Jewish Folklore and Ethnology Review, 1997; 20: 98-109.

Hui E, Chui BT, Woo J. Effects of dance on physical and psychological well-being in older persons. 2009;
49(1): e45-50. doi: 10.1016/j.archger.2008.08.006.

Leste A, Rust J. Effects of dance on anxiety. Am J Dance Ther, 1990; 12: 19-25.

Maraz A, Kiraly O, Urban R, Griffiths M, Demetrovics Z. Why do you dance? Development of the Dance Motivation Inventory (DMI). Plos One, 2015; 10(3): p.e0122866.

Mavrovouniotis FH, Argiriadou EA, Papaioannou CS. Dance: Psycho-physical effects: Greek traditional dances and quality of old people's life. Journal of Bodywork and Movement Therapies, 2010; 14(3): 209-218.

Murcia CQ, Kreutz G, Clift S, Bongard S. Shall we dance? An exploration of the perceived benefits of dancing on well-being. Arts \& Health, 2010; 149-163. https://doi.org/10.1080/17533010903488582

Olvera AE. Cultural dance and health: A review of the literature. American Journal of Health Education, 2008; 39(6): 353-359.

Parker SL. Phamily stepper [Internet]. 2015 [cited 2018 Mar 24]. Available from: www.phamily stepper.com

Rosenberg M. Society and the adolescent self-image. Princeton, NJ: Princeton University Press, 1965.

Schwarz L, Kindermann W. Changes in beta-endorphin levels to aerobic and anaerobic exercise. Sports Med, 1992; 13(1): 25-36.

Spitzer RL, Kroenke K, Williams JB, Lowe B. A brief measure for assessing generalized anxiety disorder: the GAD-7. Archives of Internal Medicine, 2006; 166(10): 1092-1097.

Taylor J, Taylor C. Psychology of dance. Champaign, IL: Human Kinetics Publishers, 1995.

Teffera $\mathrm{T}$. The role of traditional music ampng east Africa society: The case of selected Aerophones in proceedings the 6th International meeting on folk musical instruments, Martin Luther University Hall-wittenberg, Germany, 2006.

Zilidou B, Duka S, Tsolakis M. The results of an intervention program of traditional dances, as a recreational activity, improving the quality of life of senior citizens at the Municipality of Thessaloniki. Hellenic Journal of Sport \& Recreation Management, 2015; 12(1): 13-25. 